\title{
A sabedoria do compromisso com o lugar
}

ARACY AMARAL

$\mathrm{P}$

ARECE-NOS freqüentemente esgotado o debate, já agora de décadas desde Austin (1975), arrastado em congressos e simpósios por toda parte ao longo deste período, sobre a problemática da identidade, da pluralidade cultural, ou, como se quer nestes últimos tempos, do fenômeno dos deslocamentos transcontinentais. As discussões, porém, continuam, agora de ambos os lados, quando mais recentemente Europa e Estados Unidos nos expóem e tentam decifrar a esfinge de nossa circunstância ou dela em relação também a eles. Essas discussóes parecem infindáveis a intelectuais e críticos da América Latina à medida em que significam a nossa diferença com relação ao meio artístico dos países desenvolvidos, afetando o enfoque dos meios cultos de nossa arte, do período colonial e do contemporâneo. É como se fosse uma realidade da qual nos parece impossível fugir. $\mathrm{O}$ impasse aprofunda-se nestes dias em que os regionalismos parecem acirrar-se e os grupos com afinidades se fecham sobre si mesmos (mesmo após as alteraçôes da nova geografia política da Europa), rejeitando a facilidade do contato mais veloz, ao menos em termos de rapidez de comunicação. $\mathrm{E}$ como nos lembra o teórico de literatura argentino, porém atuante no Brasil, Raul Antelo (1993): “A constatação é alarmante: cada vez mais as idéias são regionais. É fácil ver nesta situação um dos avatares da modernidade: um liberalismo sem ilusões que padece sem perspectivas de cosmopolitismo. É duro ver que, estancados a meio caminho na estabilização de um sistema de intercomunicação cultural, assistimos, atônitos, à sua crise e liquidação" (1).

Coerente por sua procedência, a obra de arte em si mesma em países culturalmente periféricos mantém-se de acordo com a tipologia adquirida no período colonial e século XIX, ou seja, aponta, do ponto de vista formal, para um hibridismo natural. Informação erudita e realização popular, ou seja, de mão-de-obra a partir do desafio que cada encomenda solicitava, mão de obra analfabeta em sua maioria, em particular no Brasil e, portanto, desprovida de maior racionalidade, paralelamente à sua habilidade artesanal e a seu talento incomum na cópia de modelos.

Mário de Andrade, escritor e teórico do modernismo brasileiro, nos lembra que há sempre uma dose de criatividade em toda a imitação. E eu diria que o canhestro foi sempre visto na América Latina como a porção de nossa criatividade 
seja no estilo tekitki mexicano, por exemplo, como na peculiar estilizaçăo e relevos planiformes da talha da região peruano-boliviana, como na pintura cuzquenha. O mesmo dar-se-ia na pintura brasileira do século XVIII, tanto no Nordeste açucareiro (Bahia, Pernambuco), quanto na região de Minas Gerais, no período do auge da extração do ouro e diamantes do mesmo século, assim como nas belas imagens hieráticas religiosas, em barro policromado, da região de São Paulo do século XVIII.

A pintura acadêmica do século XIX, embora a partir de ensinamentos e modelos da escola neoclássica francesa, também apresentaria, no Brasil, uma mestiçagem de resultados que os europeus classificam quiçá como pintura de segunda categoria, embora para nós represente o marco de um internacionalismo mais à la page se comparada com a produção do período colonial, por sua familiaridade imediata com os mestres acadêmicos. Neles, os brasileiros contemplados com os Prêmios de Viagem se nutririam durante todo o século passado. Ou seja, continuávamos seguindo os modelos sem atentar muito para nossa realidade, que somente começa a ser observada no paisagismo na pintura, a emergir nas três últimas décadas do século. $\mathrm{E}$, curiosamente, apareceria também nas naturezas mortas, gênero que se inspira nos frutos da terra embora, formalmente, o modelo seja o da natureza morta européia. Timidamente, contudo, e menciono essa discrição pelo pequeno formato destas pinturas, timidez baseada, sem dúvida, num incipiente mercado de arte, que só poderia começar a existir caso houvesse uma prosperidade de uma burguesia emergente, só detectável a partir de fins do século XIX.

Qual a alteração, se ocorre de fato, com relação aos artistas modernos e contemporâneos? Em que sentido pode-se assinalar uma autonomia de vôo com relação aos movimentos internacionais em nossos países, neste século? Estas são algumas das questōes que nos colocamos, assim como diante da obra de cinco artistas deste século: Tarsila, Volpi, Hélio Oiticica, Cildo Meirelles e Marcos Coelho Benjamin. Há denominadores comuns nas obras destes artistas a nossos olhos? Como os críticos europeus viram ou vêem suas obras?

Uma receptividade mais aberta frente às novas tendências, um entregar-se (para usar a expressão de Marta Traba) mais rápido diante do que se passava em Paris, Ulm, ou Nova York é o ponto mais determinante da alteração de postura dos artistas modernos e contemporâneos brasileiros frente aos do periodo colonial ou século XIX. Além da receptividade, um estado de atenção e interesse pelo que se passa nesses grandes centros. No século XIX havia mestres acadêmicos a serem seguidos, tipo Horace Vernet e Cabanel. No século XX tivemos as vanguardas que cantavam as últimas inovaçóes, e o novo passou a ditar as regras aos artistas inquietos. 
Outro elemento diferenciador importante que poderíamos mencionar seria a conscientizaçáo pelo dado local entendido como realidade circundante. $\mathrm{E}$ a primeira vaga a nos chegar, nesse sentido, é a influência do clima propício à sedução de outras culturas que interessam aos modernos, como a precolombiana, a norte-americana do jazz, a do tango argentino etc. chegadas como exportaçóes à Europa depois da I Guerra Mundial.

É por essa razão que Tarsila não ignora poder o dado brasileiro interessar a um público ávido de inovaçóes em Paris dos anos 20. E, inconscientemente ou não, ocorre a emergência de algo que se poderia denominar de internacionalismo brasileiro, vigente até hoje, e que já transparece na obra de artistas modernistas. Ou seja, a informação internacionalista transmitida a partir de um referencial local do ponto de vista da visualidade (o caso de Tarsila e Di Cavalcanti), ou mesmo como temática, constátável no trabalho dessa década de Rego Monteiro.

Depois da despreocupação com as vanguardas nos anos 30 , motivada pela problemática social e política da época, o pós-guerra traria novas tendências, que começam a ser observadas e seguidas no Brasil na segunda metade dos anos 40 . Primeiro um expressionismo, rapidamente substituído pelas tendências abstratas, em particular, construtivistas. Essa tendência, com um olho no concretismo de Max Bill, intensifica-se com a fundação de novos museus em São Paulo e no Rio de Janeiro, e com a Bienal Internacional de São Paulo. A partir de então o internacionalismo passa novamente a primeiro plano naquele momento, por parte de muitos jovens artistas brasileiros.

A pulverização por várias capitais do Brasil de novos centros artísticos com atividade cultural, como Belém, Fortaleza, Recife, Belo Horizonte, Porto Alegre e Curitiba depois da fundação de Braślia, resultou num fenômeno que substituiu a concentração da produção artística de prestígio no Rio de Janeiro e em São Paulo. Muito embora estas duas cidades detenham o maior número de criadores pela intensidade de sua vida cultural, assim como de mercado, no caso de São Paulo, uma produção local nos novos centros distingue sua criação visual desses dois centros maiores. E o caso de Belém, Goiânia e Belo Horizonte, que mantêm núcleos de artistas com afinidade com uma tradição plástica local.

Nos artistas que estamos tentando analisar - Tarsila, Volpi, Oiticica, Cildo Meirelles, Marcos Coelho Benjamin - há como denominador comum o fato de que as obras de seus períodos máximos derivarem da sensibilidade do artista diante do ambiente brasileiro: ambiente rural, em Tarsila; suburbano ou proletário, na pintura de Volpi; ambiente da marginalidade urbana, no período máximo do intelectual Oiticica; urbano classe média, nos trabalhos conceituais de Cildo Meirelles; e urbano de tradição artesanal fortemente arraigada, de Marcos Coelho Benjamin. 


\section{Tarsila}

No caso de Tarsila, o primeiro pela ordem cronológica de sua contribuição, este dado é mais evidente (como o seria em Di Cavalcanti), por sua preocupação explícita, a partir de 1923, em fixar temas e imagens do Brasil a partir de resoluções formais emprestadas da Europa. Por esta mesma razão, sua pintura é mais deglutível na França pelos referenciais da Escola de Paris, visíveis em suas pinturas até por volta de 1930 .

Se é verdadeiro que só estamos aptos a apreciar aquelas obras com as quais temos um repertório comum, a inteligência de Tarsila fez com que se fundisse a racionalidade apreendida com Lhote, Gleizes e Léger, embora em breve aprendizado, com a magia colorida da temática popular do interior fazendeiro. Nem por isso deixamos de registrar sua insegurança não-declarada, porém visível nas molduras encomendadas a Pierre Legrain, festejado artista da tendência art déco parisiense. Essas molduras, que fizeram com que muitos quadros de Tarsila fossem denominados de tableaux-objets quando de sua exposição em Paris, talvez significassem para a artista uma coexistência com o meio artístico francês do momento, uma maneira de induzir o público da capital francesa à aceitação de sua pintura, tendo Legrain como mediador entre uma tendência em voga localmente. Afinal, que é uma moldura senão a delimitação formal entre a imagem virtual e o espaço real? No caso desta colaboração Tarsila/

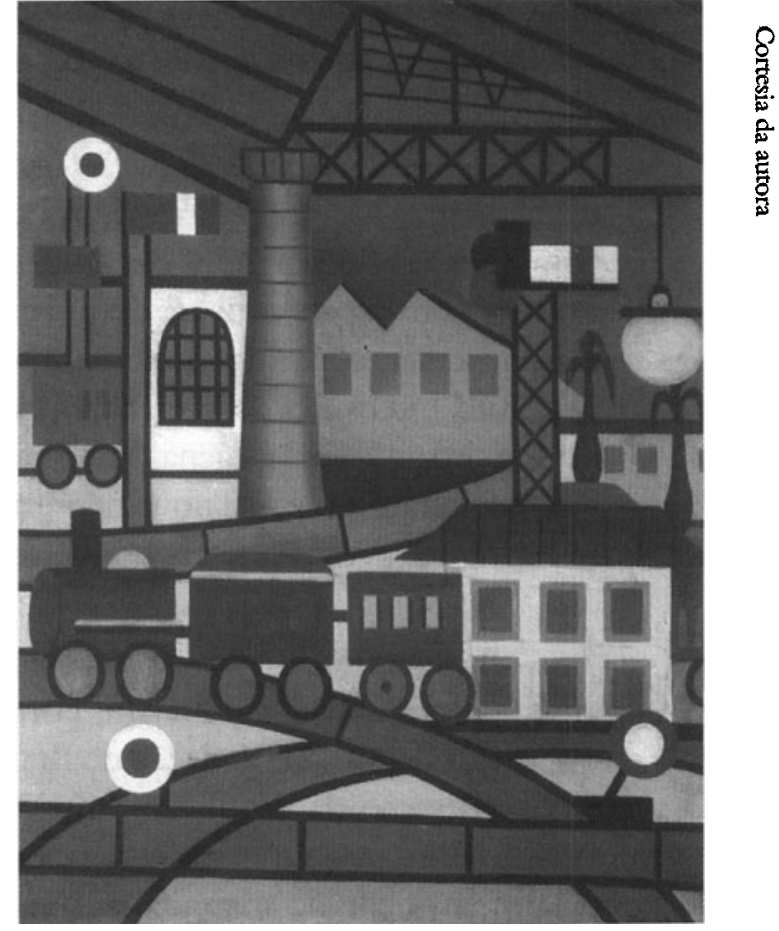

Tarsila do Amaral, A Gare, 1925, Col. R. Chaim, SP. Legrain ocorre então uma coexistência de criaçóes paralelas, de Legrain emergindo um discurso visual paralelo ao da pintura de Tarsila, em concessão desta a modismo talvez desnecessário, apesar de sua originalidade.

Quando de sua primeira individual em Paris, em 1926, as críticas e resenhas da mostra referem-se com frequiência ao exótico de suas telas, à época de fatura impessoal deliberada; assim como mencionam a influência de Léger, simultaneamente ao frescor e ingenuidade de sua pintura. Esse frescor de sentimento é também mencionado pelo Journal des Débats (1926) como um dado que "uma suficiente dose de inteligência ordenadora não sufoca (2). 
De qualquer maneira, o natipo e o exótico constituem a atração de sua exposição do ponto de vista europeu, embora um comentarista de Vie, no mesmo ano, tenha chamado a atençáo para a "aliança de uma inspiração exótica muito franca e de uma técnica apurada que não fica aquém das pesquisas mais modernas” (3).

O prestígioso crítico Maurice Raynal, deLIntransigeant (1926), já expressara com antecipação algo que nem os brasileiros da época diziam com todas as letras, ou seja, que o trabalho de Tarsila "deve marcar uma data na história da autonomia artística do Brasil” (4).

\section{Volpi}

Alfredo Volpi parte da temática de seu ambiente urbano proletário - ou da paisagem - com figuras, situaçóes de descanso e lazer do operário, tratando o assunto primeiramente de maneira impressionista, com acento forte na luminosidade e fatura pastosa; numa fase seguinte, conhecida como periodo de Itanhaém (1939-42), o desenho emerge com clara nitidez, a cor aplicada dentro

Alfredo Volpi,

Bandeirinhas, anos 50, têmpera

sem tela.

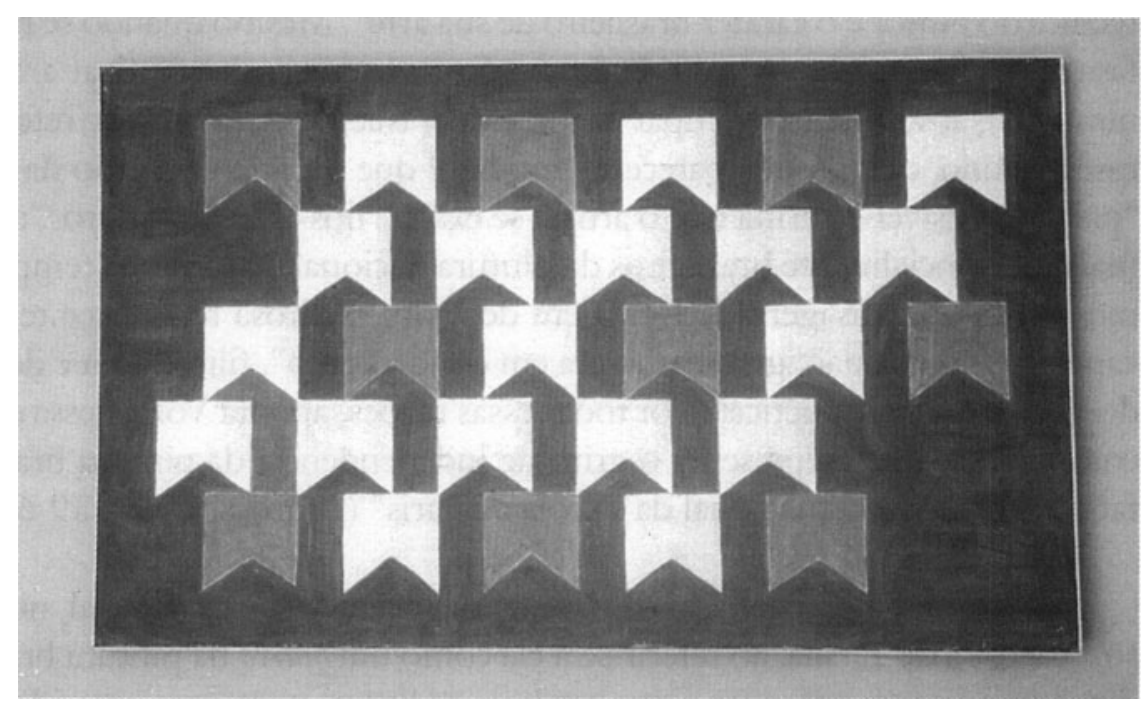

de limites bem-delineados, possivelmente fruto da observação de um naif que the esteve muito próximo - Emigdio de Souza - embora de presença extremamente discreta na arte brasileira. Mais adiante, na primeira metade dos anos 40, o expressionismo domina suas imagens numa tendência que, na época, era assinalada como um gosto internacional por parte de artistas jovens, embora a preocupaçầo fosse claramente cromática e um gestualismo novo dirigisse suas pinceladas com uma liberdade que nos traz à memória, em seu trabalho, a influência densa - e nem sei se reconhecida pelo próprio Volpi - de um grande artista como 
Ernesto de Fiori. A temática continua, entretanto, fiel ao ambiente de bairro, do pequeno arrabalde, de vilarejo do interior paulista.

Em inícios dos anos 50, Volpi passa a observar com acuidade especial os primeiros pintores concretos, em exemplar reducionismo e economia cromática. A visível aplicação manual da pintura, seu apego ao artesanato, assim como seu ponto de partida continuam sendo paisagem urbana, detalhes de decoração de festas populares e um sem-número de variações em torno ao mesmo tema, que desenvolverá ao longo dos anos 60, 70 e ainda 80.

Se era inerente à pintura de Volpi a preocupação formal, em particular cromática, não menos desvinculada de sua obra é essa inspiração popular, detectável por todos. Daí porque consideramos que essa visualidade, identificável com nosso entorno, sempre foi uma constante nos artistas respeitados como tendo projetado um veio de nossa realidade. Quando Mário Pedrosa, estimulador do construtivismo dos anos 50, escreveu o texto $O$ mestre brasileiro de sua época, abordando a pintura de Volpi, ele acentuou que dois elementos "mais facilmente verificáveis" se apresentavam na exposição que analisou: "a insuperada mestria técnica do pintor e o caráter brasileiro de sua arte". Mesmo quando se refere à sua fase expressionista dos anos 40 , Pedrosa não pode deixar de enfatizar a "força monumental, absolutamente ímpar na pintura brasileira". Exatamente referindo-se a esse período, que muitos parecem ignorar, é que o crítico, ao lado da menção à "palheta sensível", afirma que o artista se exalta "nos tons mais puros, mais ricos, mais substancialmente brasileiros da pintura nacional de todos os tempos". Mesmo diante das paisagens de Itanhaém de Volpi, Pedrosa reconhece ter o pintor captado "a nossa paisagem como era em estado bruto", filtrando-a e depois dando-nos "a essência poética". Por todas essas razōes, aponta Volpi nessa exposição, como aquele que "representa o grito de independência da pintura brasileira em face da pintura internacional da Escola de Paris" (Pedrosa, 1981: 59-62) (5).

Portanto, algo parecido com o que escrevera Maurice Raynal, nos anos 20 sobre a obra de Tarsila, ao referir-se a ela como um marco na pintura brasileira. $\mathrm{O}$ que é importante enfatizar é que até hoje se busca, portanto, uma identificaçáo entre a obra e o lugar, por assim dizer. Ou seja, por mais internacionalista que seja a aspiração dos meio ditos cultos, há sempre implícita a ansiedade por marcar uma originalidade própria de um espaço/tempo.

\section{Oiticica}

Nos anos 60, Hélio Oiticica, um artista que fazia arte ambiental, segundo a terminologia dessa década, e hoje freqüentemente visto como conceitual a despeito de sua próprias idéias, registrou a propósito do conflito/coexistência entre o universal e nacional: "O problema da imagem se coloca aqui objetivamente - 
porém posto que é universal, também proponho este problema num contexto que é tipicamente nacional, tropical e brasileiro. Eu queria enfatizar esta nova linguagem com elementos brasileiros, uma tentativa extremamente ambiciosa de criar uma linguagem que fosse nossa, característica de nós, que se ergueria contra a imagética internacional de pop e de pop arte, nas quais estava submersa uma boa parte de nossos artistas" (6).

Aliás, essa afirmação de Oiticica é conflitante com a visão que se tem de sua obra a partir de uma ótica extremamente

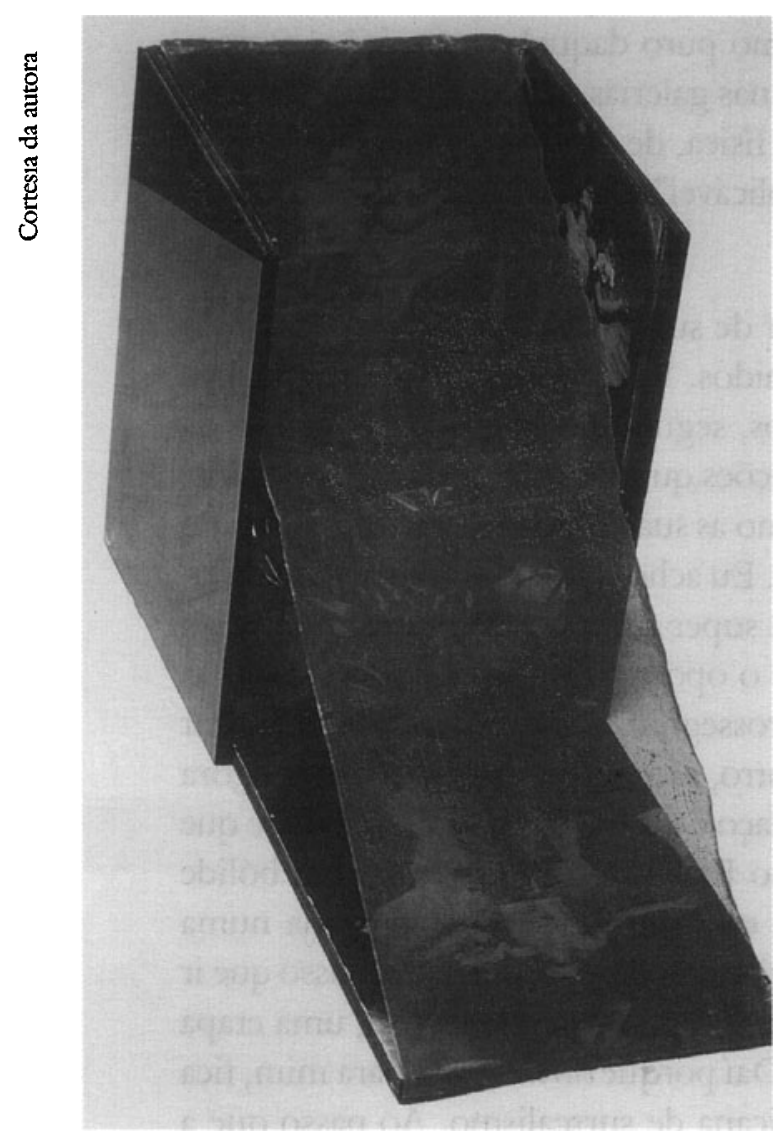
internacionalista como transpareceu, a meu ver, na retrospectiva que o consagrou em 1992, a partir da circulante iniciada no Jeu de Paume. Enfatizou-se então, de maneira particular, a assepsia do ambiente conceitual. Quanto à obra de Oiticica, poderia ter sido também assim qualificada, além de ser visceralmente nacional em sua inteligência rápida, $\mathrm{em}$ sua visão de mundo plena de humor $\mathrm{e}$ irreverência. Mesmo quando estava vivendo em Nova Iorque, registramos em. entrevista que Oiticica menciona as pessoas que vêm e perguntam: "Quando é que você volta dos United States?" Eu digo: "Eu nunca volto! Estou sempre indo! Eu nunca fui!" Aí dizem assim: "Você não tem saudades?" "Como é que eu vou ter saudades? Eusou o Brasil. Eu sou a Mangueira. Eu comi a fruta inteira. Não deixei pedaços para vir buscar depois. Eu sempre tou indo, nunca tou voltando" (7).

Helio Oiticica, Poema-Caixa, homenageando seu amigo Cara-de-Cavalo, 1965-66, Col. G. Chateaubriand, RJ.

Nesse mesmo depoimento Oiticica, referindo-se ao Parangolé, disse: "E por isso que o Parangolé é o anti-folclore. Anti-folclore não, aliás, ele torna possível que ofolclore nunca seja ofolclore. Folklore é uma coisa ainda ligada à terra" (8).

Ao mesmo tempo, Hélio Oiticica era lúcido com relação à sua aspiração de universalidade, de possibilidade de cosmopolitismo, assim como de relacionamento com o meio-ambiente, característica bem brasileira (9). 
Para Oiticica a diferença entre uma criação folclórica e o evento Tropicália é que "as imagens em Tropicália não podem ser consumidas, não podem ser apropriadas, levantadas ou usadas para objetivos comerciais ou chauvinistas. Pois o elemento de experiência direta vai além do problema da imagem".

Neste ponto está também a diferenciação da arte puramente conceitual e a criação de Oiticica, que não prescinde dessa mesma experiência direta, vivencial, sensorial, distante, portanto, do cerebralismo puro daquelas exposições maçantes, plenas de textos para se ler, que víamos nas galerias de Nova Iorque nos anos 70, simulacros de ciência, de física sem ser física, de filosofia sem ser filosofia, e sempre rotuladas de arte, denominação "aplicável" a qualquer manifestação.

Oiticica percebia com clareza o lugar de suas propostas vis à vis das obras que estavam sendo criadas nos Estados Unidos. Referindo-nos a seus trabalhos ambientais dos anos 60, como distingui-los, segundo a proposta do artista, da informação norte-americana? Nas conversaçôes que tivemos em 1977, ele reafirma que mesmo nessa época ele percebia como as suas criaçôes anteriores diferiam "bastante da coisa environmental americana. Eu acho que o enfoque norte-americano das coisas ambientais é mais na linha super-realista e não tão sintética, ao passo que as minhas coisas são exatamente o oposto. Eu nunca poderia fazer as coisas de Christo, nem earth works...". E prosseguiu, nesse depoimento,: “...Por exemplo, os bólides (1963), com terra dentro, são muito mais modernos agora do que earth works. Porque aquilo é um pedaço de terra. Tinha até um bólide que planejei mas que nunca fiz, e um dia irei ao Brasil só para fazer: era um bólide com terra do morro da Mangueira. Toda essa mitificação é sintetizada numa coisa, sem ser isso de quadro ou escultura, é um pedaço de coisa. Ao passo que ir a um lugar para fazer uma coisa (houve um tempo que eu fazia isso, uma etapa dos bólides, eu chamava de apropriações). Daí porque earth works, para mim, fica uma coisa ligada muito a uma visão americana de surrealismo. Ao passo que a minha coisa vem já de outra coisa, talvez de origem européia. Talvez, não, certamente. Européia, que é mais sintética. E citaria essa evolução, que vem dos construtivistas" (10).

Por outro lado, convém sempre lembrar que à contra-mão de sua visualidade aparentemente anárquica dos parangolés e ninhos está o rigor de uma herança científica herdada de seu pai - José Oiticica (entomologista e precursor da fotografia abstrata no Brasil) -, além de sua prática de arte concreta. Construção, limpeza, 
clareza conceitual o acompanham sempre, paralelamente à sua produção como artista/ passista da Escola de Samba da Mangueira.

\section{Cildo Meirelles}

Menos urbano e mais visceralmente ligado à terra brasileira é Cildo Meirelles, artista que, como já registramos, cria, do ponto de vista artístico, atuando como sobre um fio de navalha, conciliando, por extraordinário que possa parecer, o conceitual dos anos 70 , que sempre transpareceu $\mathrm{em}$ suas propostas, à referência ao cotidiano. A especulação intelectual esteve sempre aliada, em seu trabalho, à problemática indigenista, à violência política, à exploração do subdesenvolvido pelo desenvolvido. Simultaneamente, estas açôes ocorrem visualmente impondo-se o conceitual como imagem. Há mais de vinte anos atuando no meio artístico brasileiro, Meirelles se impôs lentamente, dentro do ritmo pausado de suas concepções, revelandose finalmente como o melhor criador na exposição Missão/Missões (curadoria de Frederico Moraes) em fins dos anos 80. Esse mesmo trabalho (1987), inspirado nas missóes jesuíticas do extremo sul do país, selecionado para Magiciens de la Terre, chamaria a atenção de grande número de diretores de museus e curadores fazendo com que, a partir de

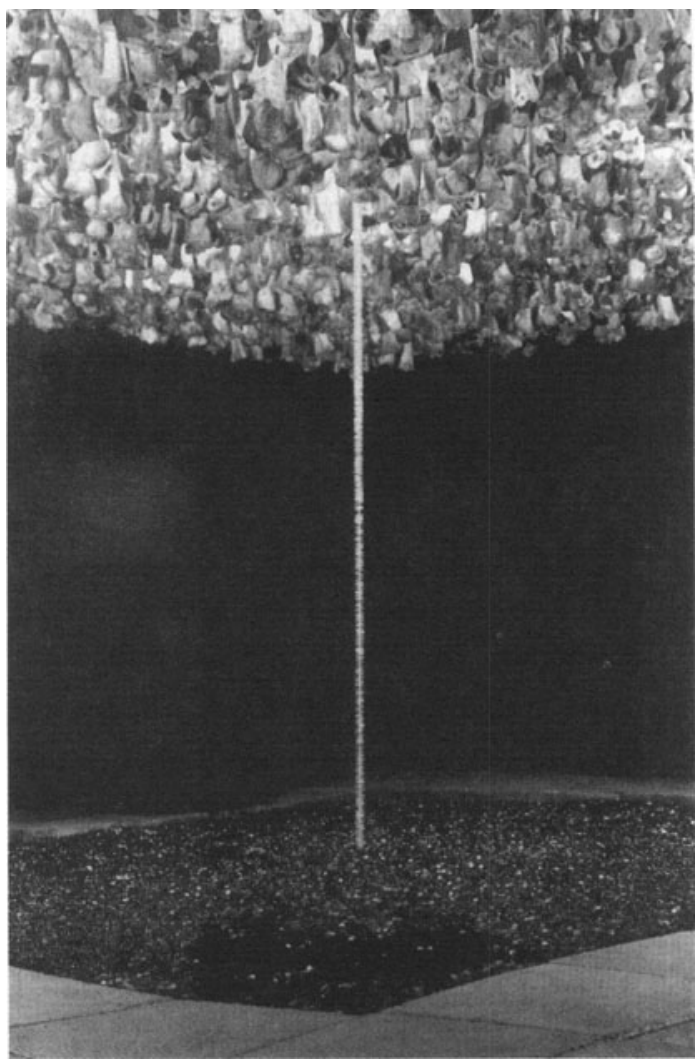

Cildo Meirelles, Missão, Missões, instalação (coluna de hóstias, ossos e moedas), 1987. então, Meirelles passasse a ser solicitado no circuito internacional. Este trabalho, assim como Cinza (Gris) já pertence a um período atual de suas preocupações. Nos anos 70, contudo, cruciais em sua contribuição, ele se utilizou de estratagemas para enfrentar com criatividade seu discurso poético/visual, dentro da linha que Guy Brett (1990:47) chamaria recentemente de antecipador da "idéia usada como uma tactica de resistência numa escala de massa no Chile alguns anos depois do golpe de Pinochet" (11).

Com a acuidade que lhe é peculiar, Guy Brett pôde ver também em Cildo 
Meirelles uma característica que, realmente, lhe é própria, ao dizer ainda, no mesmo texto elaborado para Transcontinental que, mais que um desenvolvimento linear, seu trabalho apresenta uma meditação contínua envolvendo o "relacionamento de fine arts com cultura popular", aproximando-se esta visão de nosso parecer sobre a trajetória do artista.

Desta forma, não há de sua parte necessidade de rotular seus trabalhos como de preocupação social, comprometidos, ou conceituais posto que estes atributos derivam tacitamente de observação de suas obras. Entre a proposta e a execução, contudo, há em Meirelles, uma distância que, ela sim, nomeia ou submerge o projeto. $\mathrm{O}$ artista é dependente de circunstâncias favoráveis ou não à sua concretização. Por outro lado, pela própria natureza dos projetos de Cildo Meirelles, eles pertencem não só a um determinado espaço, como são determinados intensamente por seu tempo. E o caso da série Circuitos ideológicos, realizadas nos anos 70 no Brasil, assim como Fiat Lux. São obras por assim dizer, que não têm voz, fora de seu instante. E este dado não é desconhecido do artista, contagiável pela realidade imediata nessa sofrida década dos setenta.

\section{Benjamin}

O caso de Marcos Coelho Benjamin está vinculado à tradição artesanal do estado de Minas Gerais, região de ouro e diamantes no Brasil do século XVIII. Hoje, Minas é o principal reduto da produção do ferro no Brasil. Ao mesmo tempo, persiste uma tradição poética em seus artistas, um apego ao artesanato (seja de origem portuguesa do Minho - com suas lâmpadas de metal perfurado manualmente, seja o artesanato de origem africana, em artistas populares que trabalham diretamente na madeira). Em meio a esse entorno, que tem muito de religiosidade como poucas outras áreas do Brasil, surgiram artista de tradição construtiva, como o escultor Amilcar de Castro, ou o pintor Celso Renato, recentemente falecido. $\mathrm{O}$ primeiro, contudo, mesmo trabalhando com formas geométricas realizadas em

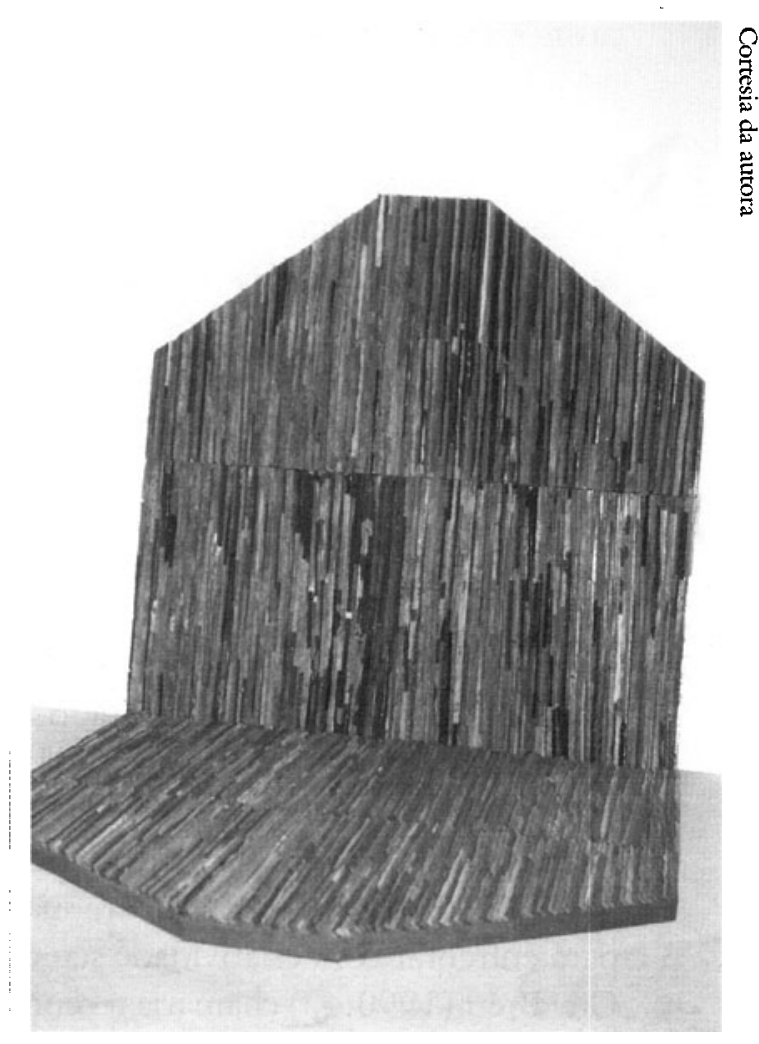

Marcos Benjamim, Sem Título, (zinco sobre madeira), 1989. espessas lâminas de ferro de sua regiáo, seu corte, ou seu projeto de dobragem da 
placa de ferro trai muito do gestual, do impulso instintivo, distante, portanto, da racionalidade construtiva. Sobretudo quando sabemos que a pátina da oxidação sobre suas superfícies ou seja, o trabalho do tempo, é elemento constitutivo de suas criações tridimensionais, assim como a linha que se insinua nas frestas de suas construçóes, como sutil visualidade luminosa, espaço/forma virtual. Já Celso Renato nos legou uma produçáa de trabalhos em pintura que, se não é vasta, obtém um máximo de economia cromática, com elementos abstrato-geométricos sobre suportes de madeira usada e envelhecida por sua vivência. São pinturas de aparente pobreza como material, assim como de grande beleza no reducionismo de suas composições.

Sem prosseguir com outras mençóes, a essa linhagem de uma verdadeira escola mineira pertence Marcos Coelho Benjamin. Iniciando-se como artista gráfico, em comics ou desenhos de humor, em meados dos anos 80 já apresentava trabalhos tridimensionais de pequeno porte, porém com um clima secreto que já assinalava a tradição do artesanato sobre a madeira. É dessa década sua explosão no meio brasileiro, tão marcado, com a nova geração, pelas tendências neoexpressionistas que nos chegavam como informaçăo da Europa. Seu vocabulário visual se distinguia dos jovens da geraçáo 80 . As formas encerradas em si mesmas, cônicas - circulares ou trapezóides - de grandes dimensões, de assepsia absoluta, como as que Benjamin apresentou na Bienal de São Paulo de 1989, revelavam um universo particular. A exatidão geométrića aparente cedia lugar, à aproximação do observador, ao trabalho quase filigranado do artesão. As lâminas de lata usadas, finamente cortadas e justapostas, revelavam sua origem de elemento descartado e que se transfigurava mediante tratamento quase oriental em sua paciente remanipulaçáo . Como resultado, efeito de grande beleza e poesia. Sempre abordando grandes superfícies, Benjamin agora lança mão de novos materiais, como solda elétrica, chumbo, folha de cobre, folha de ouro, sem ter deixado de trabalhar com folhas de zinco, lata, e madeira. O que me parece importante ressaltar neste artista, nascido em 1952, é a absorção do artesanato popular em sua arte, à primeira vista clean, em formas que exalam uma religiosidade peculiar pela frontalidade que as caracterizam. E o gesto elaborado e paciente, como no inventor de frisos, trai o reflexivo de sua natureza, assim como o repetitivo do artista popular de todos os séculos, simultaneamente ao hieratismo de suas grandes composiçóes.

\section{$* * *$}

A escolha subjetiva, é claro, desses artistas para análise de caso, muito embora dois deles em particular não possuam uma obra perene, que permaneça (Oiticica e Meirelles) se baseia no fato de que os cinco apresentam contribuiçôes extremamente pessoais, mantêm um olho aberto para a informação internacional e o outro atento a seu espaço, que se projetam em seus trabalhos. Se Tarsila não 
teve discípulos e seu reconhecimento no Brasil e Exterior foi realmente tardio, o mesmo sucederia com Oiticica e Meirelles. O caso de Volpi, do ponto de vista de receptividade doméstica é distinto, porquanto sua pintura foi requestada em particular a partir dos anos 60, até chegar a comprometer sua produção já difícil, quando o artista tinha mais de oitenta anos, em começos dos anos 80 . Diferenciam-se de artistas formalistas de excelente nível de qualidade, como Antonio Dias, Ligia Clark, Mira Schendel, Weissmann, Esmeraldo e tantos outros da forte herança construtivo-conceitual do Brasil, em cujas obras não transparece o dado brasileiro como uma motivação real. E, paradoxalmente são igualmente diversos por sua especulação na forma, de outros cuja inspiração no real exterior ou na interioridade foi igualmente poderosa, como é o caso de Iberê Camargo, Antonio Henrique Amaral, Siron Franco, Ivens Machado. Na observação da receptividade desse punhado de artistas contemporâneos percebe-se uma discriminação perversa a se abater sobre o segundo grupo, no Brasil, pela simples razão de que a herança do concretismo e neoconcretismo, que gerou o conceitual, produziu um esnobismo intelectual que tem favorecido nos últimos 15 anos, quiçá, os artistas das tendências mais cerebrais, olhando-se com certo desdém aqueles gestualistas ou preocupados com uma realidade reproduzível através da imagem.

O curioso é que, no exterior, quando se organizam exposiçóes de arte do Brasil ou da América Latina, deseja-se encontrar exatamente os referenciais mais explícitos para aquele público em relação à expectativa sobre o que é a criação plástica em nossos países. Do que tenho lido sobre o assunto, talvez tenha sido Homi Bhabha quem melhor soube expressar, com sensível acuidade, essa problemática, quando os outros nos olham. Assim, abordando a diferença cultural a partir do problema da identidade, ele lembra que a questão vem "do teatro do combate colonial até atingir uma crítica do valor estético e político que atribuímos à unidade das culturas, sobretudo àquelas cuja história é marcada por um longo período de dominação e incompreensão" (12). Na verdade, isso não passa de um fim utópico (a unidade das culturas) posto que, como afirma, as culturas não são nunca totalmente unificadas, nem uma relação dualista em direção às outras: ela e a outra. Daí porque, como diz ele, "Nem porque um certo relativismo supóe que nossa atitude "cultural" em falar das outras nos "coloca forçosamente em seu lugar", numa espécie de "relativismo de distâncias" (13).

O esgotamento das vanguardas colocaram a Europa e os Estados Unidos diante da criação artística de países que antes eles pouco prezavam, a não ser do ponto de vista etnológico. Aliás, fenômeno similar já ocorrera na segunda metade do século XIX (com a estampa japonesa e a escultura africana), em tentativa de busca e renovação. Daí a série hoje já bastante longa de exposiçóes da América Latina pelos europeus e norte-americanos. No entanto, sempre nos rebelamos com a bibliografia por eles construída (14), a partir de seus superficiais conhecimentos e contatos com nossa criação artística. Nesse panorama, Guy Brett é realmente 
excepcional como fenômeno, tanto com relação a artistas brasileiros quanto no que concerne à arte do Chile. Thomas McEvilley reconhece que "Quando uma cultura expóe os objetos de uma outra, o conjunto de proposiçóes e de apropriaçóes também se encontra ampliado a partir daí. Além da escala do indivíduo, do grupo de interesses, da nação e da classe internacional, a exposição enfatiza as relações entre as zonas de culturas multinacionais. O melhor exemplo é certamente a exposição, pelas culturas colonialistas ocidentais, de objetos pertencentes às culturas colonizadas daquilo que denominamos de terceiro mundo" (15).

Mas se esse discurso parece ter sido superado, suas circunstâncias permanecem intocadas. Por essa mesma razão continuam válidas as observações de LéviStrauss, citado por Pierre Gaudibert, talvez o maior fascinado da França pelas outras culturas em nível artístico, depois de Lévi-Strauss e de Blaise Cendrars, quando o antropólogo francês se refere aos dois perigos maiores "para a existência destas culturas plurais, a ausência de comunicação, e seu excesso; uma traz a introversão e estagnação, o último, homogeneização por perda dos dados diferenciais" (16).

No enfoque destes brasileiros foi nosso intuito exatamente tentar pinçar cinco personalidades que se movem no frágil limite desse excesso e dessa escassez. Seu êxito mede-se pela delicadeza com que sobrevivem ao ambiente de mass media da arte de hoje, de documentas e bienais pasteurizantes e pasteurizadas, nas quais só é apresentado e percebido aquele que acentua sua personalidade como arte, ou é fruto de um complexo de influências e de um rigoroso sistema de marketing, posto que é difícil a admissão da inocência nos circuitos da arte de hoje.

\section{Notas}

1 Raul Antelo, "Diferença e mercadoria”, "O Cataraina!", Florianópolis, jun. 1993.

2 Journal des Débats, 20 jun. 1926, Paris, trad. da A.

3 "Vie", Paris, ago. 1926.

4 Maurice Raynal, LIntransigeant, Paris, 13 jun, 1926.

5 Mario Pedrosa, "O mestre brasileiro de sua época", Jormal do Brasil, 18 jun. 1957, apud M. Pedrosa "Dos murais de Portinari aos espaços de Brasilia" ( org. A. Amaral), São Paulo, Perspectiva, 1981.

6 Hélio Oiticica, Whitechapel, Londres, fev./abr. 1969, s/ pag., trad. da A. 
7 Conversação de Aracy Amaral com Hélio Oiticica, Nova York, out. 1977, Christopher Street, texto inédito.

8 “...Porisso é que não me sinto "foreigner".(...) eu nunca me sinto "foreigner em lugar nenhum. As pessoas chegam num lugar e se sentem estranhas, eu digo "O quê? Estranho em algum lugar? Imagine, eu vou à China e já chego lá falando chinês. As pessoas chegam e ficam aqui cinco anos e não sabem pedir café em inglês”. Idem, ibidem.

9 Hélio Oiticica, Whitechapel, Londres, fev./abr/ 1969.

10 "Conversação de Aracy Amaral com Hélio Oiticica", ibidem.

11 Guy Brett, "Transcontinental, an investigation of Reality", Verso/Ikon Gallery, 1990, p. 47.

12 e 13 Homi Bhabha, "Hybridité, hétérogénéité et culture contemporaine", "Magiciens de la Terre", Centre Georges Pompidou, Musée National d'Art Moderne, Paris, mai./ago. 1989, p. 25. Esse "relativismo de distâncias". segundo $H$. Bhabha, é objeto de análise do filósofo Bernard Williams em "Ethics and the Limits of Philosophy".

14 Bibliografia está desenvolvida a partir de sua própria bibliografia anglo-saxã, raramente com consulta a um mais completo inventário de publicações de nossos países. Ver, como exemplo, de Edward Lucie-Smith, "Latin American Art of the 20th Century", Thames \& Hudson, Londres, 1993.

15 Thomas MvEvilley, "Ouverture du piège: l'exposition posmodern et "Magiciens de la Terre"”, "Magiciens de la Terre", ibidem, p. 21, Trad. da A.

16 Cit. em Pierre Gaudibert, "La Planète toute entierè, enfin...", "Magiciens de la Terre”, ibidem, p. 19.

Aracy Amaral é professora titular em História da Arte da Faculdade de Arquitetura e Urbanismo (FAU) da USP. Dirigiu a Pinacoteca do Estado de São Paulo (1975-1979) e o Museu de Arte Contemporânea da USP. No momento é diretora do Departamento de Museus e Arquivo do Estado da Sec. Est. de Cultura de S. Paulo. É autora de vários livros, entre eles As artes plásticas na Semana de 22 (1970; 5. ed., 1992) e Arte para qué? A preocupação social na arte brasileira 1939-1970 (2 $\mathrm{ed}$. 1986) e coordenou numerosas antologias, como Arte y arquitectura en el modernismo brasileño (1978) e Arquitectura Neocolonial: América Latina, Caribe e Estados Unidos (1994).

Este texto foi apresentado no Simpósio de Zacatecas, México, em setembro de 1993, organizado pelo Instituto de Investigaçóes Estéticas, UNAM, México, DF. 